\title{
AGILITY AND COORDINATION TESTING IN HAND-TO-HAND COMBAT SPORTS
}

\author{
VLADIMIR PLATONOV, ALEKSEI NIKITENKO \\ National University of Ukraine on Physical Education and Sport, Department of History and Theory \\ of Olympic Sports, Kyiv, Ukraine
}
Mailing address: Vladimir Platonov, National University of Ukraine on Physical Education and Sport, Department of History and Theory of Olympic Sports, 1 Fizkultury Street, 03150 Kyiv, Ukraine, tel.: + 38044 2873261, e-mail: vladimir@platonov.org.ua

\begin{abstract}
Introduction. The aim of the study is to analyse existing tests for assessing agility in combat sports and martial arts, as well as to develop new tests and to test their effectiveness. Material and methods. The study involved 16 athletes at various competitive levels specialising in hand-to-hand combat. It used the following methods: review of specialised literature along with policy and normative documents, an expert survey, testing, instrumental methods of assessing psychophysical capabilities, a pedagogical experiment, and methods of mathematical statistics. Results. The article clearly delineates the concepts of "agility" and "coordination". It was found that most of the exercise tests recommended for assessing agility actually only evaluate coordination, without taking into account unexpected and unpredictable situations, which are the key components of agility. While some tests allow for the assessment of agility, they are based on motor actions which are non-specific for combat sports. Moreover, the use of computer-based techniques for studying the visual-motor reaction has proven to be ineffective for assessing agility in sports. Conclusions. The article proposed three variants of specialised tests for assessing agility in motor actions specific for hand-to-hand combat. According to the results of all the three tests, the programme proposed for the development of agility and coordination caused a significant improvement in the level of agility in six months.
\end{abstract}

Key words: agility, coordination, testing, hand-to-hand combat.

\section{Introduction}

Agility and coordination abilities, as the most important qualities in the physical preparedness of athletes specialising in wrestling and martial arts, largely determine the effectiveness of the training process and participation in competitions. However, the fact that issues related to testing these qualities have not been adequately addressed limits the possibility to control the effectiveness of the training process and competitive activity of athletes and hinders the development of the methodology for training agility and coordination. It also makes it difficult to study the role of these qualities in success in various combat sports and their relationship with the technical and tactical skills of the athlete as well as with other motor qualities.

The effectiveness of the training process aimed at developing agility and coordination abilities, as well as that of the testing of these qualities, is determined by the clarity and unambiguity of the definitions of the terms "agility" and "coordination abilities" or "coordination". Unfortunately, to date there is no agreement on this issue in the expert literature. Some experts emphasise the fundamental differences between these concepts, regarding agility and coordination as different motor qualities [1, 2], whereas others consider them as a single multifactor quality $[3,4]$.

In our work, we distinguish these concepts in accordance with the ideas of N. A. Bernshtein, a prominent specialist in this field [5], whose views have been creatively developed by many scholars $[1,6,7]$.

Agility should be understood as the ability to perform effective motor action in unexpected and difficult situations that require ingenuity and appropriate motor responses [2], while coordination is the ability to take effective action with a complex dynamic and space-time structure in known, more or less learnt conditions, which are devoid of uncertainty and unpredictability factors $[1,8,9]$.

Different types of coordination abilities (the ability to control the dynamic and spatial-temporal parameters of movements, maintaining balance and the rhythm of movement, orientation in place and time, synchronisation of muscle activity, etc.) determine the effectiveness of complex motor actions both under stereotypical conditions and in unexpected and unpredictable situations $[7,10]$. However, the surprise factor imposes special requirements on mental and neuroregulatory mechanisms controlling movements and motor actions that are fundamentally different from those that occur when performing familiar, well-mastered movements, techniques, and motor actions $[5,11]$, and this gives grounds for distinguishing agility as an independent motor quality.

In various sports, including combat sports, a number of experts draw attention to the fact that the ability to perform coordinated and efficient motor activity without an uncertainty factor is different from the ability shown in unexpected and changing situations that require agility $[3,10]$. This is reflected in the recommendations related to the content of the training process. For example, S.N. Nikitin [12] notes that the development of agility should be an important part of the content of the training process, especially in the initial stages of multi-year training. The content of the training process aimed at the development of agility should be chosen with the understanding that agility is an independent multi-component ability, the central 
part of which is the potential of the nervous system to control movements in unusual, probabilistic, and unexpected conditions through analyser systems. Agility can be developed during training matches between wrestlers of different styles such as speed-strength, playing, or tempo-based ones. The matches between the wrestlers of different styles can broaden the range of motor actions, technical, and tactical decisions, and thanks to their psychological impact, they can significantly affect the range of the expression of agility and technical mastery [12].

An important direction in the methodology of agility training in athletes specialising in combat sports is the wide use of various kinds of distracting factors that make difficult and complicate effective motor activity in the training process and in competitive activities. Such factors may be of exogenous nature (pressure, difficult fighting style, unconventional actions of the opponent, specificities of judging, spectators' behaviour, etc.) or endogenous nature (athlete's emotional state, mood, tolerance to pain, fatigue, etc.). They significantly affect the mental state of the athlete, their physical abilities, and their ability to take efficient technical and tactical actions. Their widespread use in wrestlers' training is an effective means of increasing the load on the athlete's body and the use of physiological reserves in motor activity [13], which results in increased psycho-physiological capabilities and the ability to perform adequate motor actions in unexpected and varied situations.

As a basis for the methodology of agility training, N.V. Boychenko and Yu Shan recommend the following: the use of complex and unconventional exercises; the need for the athlete to choose the best option among several possible solutions of the motor task; changing spatial boundaries and the way of performing the exercises; increasing the complexity of the exercises and their integrated use; focus of attention on static-dynamic stability and accuracy of movements and motor actions; as well as changing the conditions of exercise performance and creating unusual situations [14].

To implement these recommendations, various general preparatory and specific preparatory exercises are used. Among the general preparatory exercises, the most effective are various types of team sports (basketball, football, and handball), including games with different numbers of players in teams in playing grounds of different sizes using balls of different sizes and weights; various kinds of jumping in place and in motion, with turns and changes in the direction of motion; acrobatic exercises (rolls forward, backward, and over the shoulder, combined with jumps, handstands, and headstands); performing exercises in unusual conditions: on sand, on grass, with eyes closed, etc. As for the specific preparatory exercises, the following ones are recommended: actions in response to unexpected cues; matches between wrestlers of different height and weight, using various techniques and tactics, etc.; various kinds of relays, including specific motor actions; the variation of technique parameters when using techniques and performing motor actions [14, 15].

Particular attention is paid to improving the efficiency of the training process aimed at developing agility, by increasing the level of emotion experienced during the teaching and training processes, as well as by using playing and competitive methods. The inclusion of technical and tactical elements, movements, and motor actions characteristic of the combat sport into the training programmes makes it possible to diversify the training process, to stimulate the interest of the athletes, and to increase the level of emotion experienced during the workouts [16].

The process of developing agility can also be optimised by incorporating aerobic exercises adapted to a specific combat sport. The effectiveness of such training can be increased through a pronounced dance style and beating rhythms of musical accompaniment; the use of aerobic exercises focused on training coordination in combination with exercises that contribute to the development of speed-strength abilities, flexibility, and endurance; the use of various equipment, such as jumping ropes, step platforms, and fit balls; the avoidance of monotonous loads; or the constant alternation of exercises with different focuses [17].

It is quite natural that the specific content of the training process aimed at developing agility, which is based on material that is diverse, activates emotion, and, most importantly, is abundant in unexpected situations, requiring quick and adequate solutions, should be reflected in the specific tests used to assess agility. However, an examination of the expert literature as well as policy and normative documents, which reflect the content of the training process for combat sports athletes and law enforcement officers who train martial arts, indicates the absence of such a relationship.

Our research has been devoted to the analysis of the existing system of knowledge in the field of testing agility and coordination abilities, the substantiation of a general approach to testing these qualities, and the development of specific tests for assessing agility and coordination in combat sports and martial arts.

\section{Material and methods}

The research compares 3 different approaches to agility and coordination testing, including a self-developed test. The validity and reliability of the tests were used as the criteria of their objectivity. The validity of a test depends on its relevance to the phenomenon being assessed. To evaluate the validity of the current test, a substantive analysis can be used to reveal the identity of the processes studied during testing and of those characteristic of the tested phenomenon, or a statistical analysis aimed at revealing a correlation between the test results and the corresponding phenomenon [18]. The reliability of the test depends on the reproducibility of the test results when testing is repeated. Reliability is ensured by the standardisation and consistency of the test content, conditions of testing, the quality of the equipment used, etc. $[19,20]$.

The study involved 16 combat sports athletes, who had different competitive levels. Their ranks in the Ukrainian classification systems ranged from the so-called second class ( $5^{\text {th }}$ top class) to the international championship class (top class). The rating was determined on the basis of an expert survey as it was done in a previous study.

To identify the relationship between the athletes' skill levels and test data, the athletes were ranked and rated (from 1 to 16), and the rating was used as an individual numerical indicator of their skills. The rating was determined by highly qualified experts $(n=5)$ taking into account the athlete's sports class and title, their achievements in competitions at various levels, the subjective evaluation of the athletes' technical and tactical skills and functional preparedness by the experts, and the effectiveness of their competitive activity during the year preceding the study.

The first test was carried out according to the N.V. Makarenko method for evaluating the sensorimotor skills of athletes using computer programs, which have become quite widespread in sport [21]. We selected five indicators that are most significant for high performance sport: simple visual-motor reaction (SVMR), complex visual-motor reaction (CVMR), functional 
mobility of nervous processes (FMNP), strength of nervous processes (SNP), and reaction to a moving object (RMO).

For an integrated assessment of the ability to regulate the dynamic, spatial, and time characteristics of movements as well as maintain balance and a sense of tempo and rhythm, a complex (second) test was used, which included dummy throws, was carried out according to a strictly defined programme. The motor test programme was as recommended by V.F. Boyko [22] for the assessment of specific endurance with an appropriate modification. The test consisted of three parts. In the first part, the subject was asked to perform 10 sweeps of the dummy alternating the right and the left sides with a standard dynamic and spatial time structure of motor actions at the maximum possible pace. The pace of the throws was reduced by one and a half times in the second part and by two times in the third part.

Testing was carried out after the standard 30-minute warmup, the specific part of which included the test elements. Mannequins were chosen individually so that their weight was about $60 \%$ of the body mass of the subject. Specific speed-strength and coordination abilities were assessed by the time required to perform 10 sweeps of the dummy at the maximum possible pace. The ability to regulate the dynamic and kinematic characteristics of the techniques was determined using the difference in the time required to perform the sweeps at a given pace (1.5 and 2 times smaller than the maximum and maximum). The stability of motor actions was determined using the difference in the time of the fastest and the slowest sweeps in each part of the test.

The third test was self-developed and will be described in the article in detail. The validity of the test was evaluated by identifying the correlation between the rating of the athletes and the time required to perform the test programme.

The following methods of mathematical statistics were used for processing the experimental data: descriptive statistics, the sampling method, and correlation analysis.

\section{Results}

An analysis of the literature which addresses the issues of testing agility and coordination abilities indicates that when it comes to testing both general (basic) agility and that which is specific, characteristic of different sports, various complex programmes of physical activity are recommended, which are based mainly on movements with sharp changes in the direction of movement, complex jumps, intense motor actions in a limited space, running combined with touching obstacles, etc. $[23,24,25]$. All these tests require a high level of speed-strength abilities, coordination of movements, as well as rational technique and speed of running, walking, and jumping.

Such tests, according to experts who recommend them [26, $27,28,29$ ], are used to test agility or to simultaneously test agility and speed abilities. However, in practice, they allow us to evaluate not agility, but coordination, which depends on neuroregulatory and psychoregulatory abilities that regulate movements and motor actions and their relationship with technique and the level of development of speed and speed-strength abilities [1, 9, 10]. This is explained by the fact that these tests are based on standard material, which is well understood by the subjects, and though it places high demands on their motor capabilities, it is not fraught with uncertainty and unpredictability. So, in these tests, there is no core component of agility, namely, the ability to solve the motor task in a creative way in unexpected and suddenly arising situations $[2,5]$.
In other cases, tests with elements of unexpectedness are recommended. For example, in assessments of agility in athletes specialising in judo [30, 31] and Greco-Roman wrestling [32], simple tests are recommended, which allow assessing agility by looking at the proportion of successful actions compared to their total number. The following tests are given as examples: ball reception from different players from different directions on cue; and landing accuracy in long jumping with different jump distances. However, there is another drawback that does not allow for the use of these tests due to the obvious violation of the validity criterion, namely, the lack of a relationship between the movements and motor actions used in the tests and the specific features of combat sports and martial arts [10,33].

The fact that lack the problem of testing agility in combat sports remains largely unaddressed is, perhaps, most clearly reflected in the modern Russian federal standards of sports training in freestyle and Greco-Roman wrestling, judo, and taekwondo. There is no mention of agility in the standards, whereas coordination is recommended to be assessed solely using the $3 \mathrm{x}$ $10 \mathrm{~m}$ shuttle run test. It is clear that this test is not only extremely one-sided and fails to assess a substantial part of coordination abilities to be covered but it is also does not fulfil the criterion of validity, since its content is not related to the structure of motor actions characteristic of combat sports. Unfortunately, here we are faced with the return of a methodological error which was inherent in Soviet sports of the 1930s-1950s and was manifested in the desire to relate the tests from the 'Ready for labour and defence' battery (Gotov k trudu i oborone, GTO) to testing the sport-specific preparedness of athletes. It is worth mentioning that such an approach to testing specific physical preparedness has become a serious problem that has been reflected in many studies of recent years $[34,35]$.

Currently, a large number of instrumental methods are used to assess agility and coordination on the basis of the analysis of visual-motor reactions along with the assessment of the speed of a simple and complex response, the speed of information processing, attention focus, spatial perception, attention distribution, visual scanning, etc. For example, one of the most popular applications for measuring and developing agility and coordination abilities, Cognifit software, includes a set of eighteen tests with different focuses, which make it possible to assess the synchronisation and coordination of motor actions, the speed of simple and complex responses, the speed of decision making in the event of difficult and changing situations, information processing speed, etc. All of the tests are based on the assessment of the speed and accuracy of the arrow movements in response to the situations appearing on the screen [36].

Such programs, which are based on the assessment of simple motor manipulations with the arrow, reflect to a certain extent the basic level of agility and coordination abilities. However, when they are applied to high performance sport, their capabilities are extremely limited due to the lack of sport-specific motor activity and associated with the manifestation of agility and coordination. In the overwhelming majority of cases, agility and coordination in high performance sport rely on the amount of specific motor memory and its organic connection with phenomena such as anticipation, intuition, and automaticity [7, 11]. As for the existing programs for testing visual-motor capabilities, they do not activate the mechanisms that are the basis for effective responsiveness and motor response in unexpected and difficult situations that require agility and coordination abilities $[2,25,37]$.

In general, an analysis of the structure of agility and coordination along with the methodology of the testing and develop- 
ment of these qualities indicates the need to develop specific tests that correspond to the specific features of combat sports and martial arts. Coordination abilities should be tested with sport-specific tasks, which are organically related to the content of training and competitive activities. They can be assessed by examining the speed of specific motor actions, the time required for mastering technical skills and motor actions; the time required for the restructuring of motor activity in response to a changed situation; the accuracy of motor actions evaluated using dynamic, spatial, and temporal characteristics; the ability to maintain stability after a balance disturbance; the consistency of motor action performance in varied situations (various positions of the body, objects, functional states, etc.). As for agility, its testing should be based on the assessment of the effectiveness of motor actions in difficult, unexpected, and hardly predictable situations. The rationality of the motor response, its correspondence to the situation that has arisen, and the speed of response should be assessed [7, 33, 38].

Before proceeding to the substantiation and development of specific tests for assessing coordination and agility in combat sports athletes, we considered it necessary to check the validity of widely advocated computer methods for studying psychoregulatory and sensorimotor reactions based on the assessment of eye-hand coordination during various manipulations with the mouse arrow.

\section{Validity of computer software for 'eye-hand' testing of cognitive and psychomotor capabilities}

In modern psychophysiology, computer tests have become widespread, replacing blank tests ('pencil-paper' and 'eye-hand' forms). Computer tests have made it possible to significantly intensify and diversify the process of testing and processing of the results, as well as to diminish the impact of the person conducting the test. In particular, various complex tests aimed at studying the cognitive and psychomotor capabilities of athletes are quite widespread in sport. They are based on the assessment of the speed and accuracy of the response to the tasks appearing on the computer screen with an arrow ('eye-to-hand'). These tests are focused on assessing the accuracy of perception of time and space, the speed of simple visual-motor and audio-motor reactions, the speed of complex visual-motor reactions, the accuracy of response to a moving object, performance with a lack of time or information, stability of response, etc.

We have verified the validity of tests based on the assessment of eye-hand coordination for evaluating two psychomotor capabilities, agility and coordination, in athletes specialising in a sport which is particularly challenging with regard to these qualities, that is hand-to-hand combat.

Table 1. Correlation coefficients between athletes' rating and their psycho-physiological indicators $(\mathrm{n}=16)$

\begin{tabular}{|c|c|c|c|c|c|c|}
\hline Indicator & Rating & $\begin{array}{c}\text { SVMR, } \\
\text { ms }\end{array}$ & $\begin{array}{c}\text { CVMR, } \\
\text { ms }\end{array}$ & FMNP, s & $\begin{array}{c}\text { SNP, } \\
\text { signal }\end{array}$ & $\begin{array}{c}\text { RMO, } \\
\text { ms }\end{array}$ \\
\hline Rating & 1.00 & & & & & \\
\hline SVMR & 0.05 & 1.00 & & & & \\
\hline CVMR & -0.16 & $0.51^{*}$ & 1.00 & & & \\
\hline FMNP & 0.11 & -0.04 & 0.19 & 1.00 & & \\
\hline SNP, signal & -0.08 & -0.42 & -0.19 & -0.46 & 1.00 & \\
\hline RMO & $-0.53^{*}$ & 0.10 & 0.42 & 0.22 & -0.19 & 1.00 \\
\hline
\end{tabular}

Note: * - correlation coefficient is statistically significant at $\mathrm{p}<0.05$.
The results of the study have confirmed the opinion of experts according to which each of the five indicators reflects the specific capabilities of sensorimotor skills that are associated with certain sensory and motor components of the movements as well as their regulation, control, and adjustment. This was convincingly shown by the correlation coefficients between various indicators (Tab. 1). Only in one case was a moderate correlation found between the indicators of simple and complex visual-motor reactions $(\mathrm{r}=0.51, \mathrm{p}<0.05)$. In all other cases, no correlation was revealed.

What was also of interest with regard to the aim of our study was the relationships between the rating of the athletes and each of the five indicators. The results obtained are predictable but contradict the approaches and assessment results reported in a large number of studies on the psychomotor skills of athletes which used eye-hand computer tests (see Tab. 1). Only in one case was there a significant correlation between the athletes' rating and their sensorimotor indicator; a moderate correlation $(\mathrm{r}=-0.53, \mathrm{p}<0.05)$ was found between the athletes' skill level and the time of response to a moving object, a complex sensorimotor reaction related to the assessment of the object position, the perception of its movement, and the corresponding response.

However, in general, the results of our study clearly demonstrate the futility of studying sensorimotor abilities of qualified athletes on the basis of eye-hand or arrow-screen computer testing. This is understandable, given that in the study of specific sensorimotor abilities, a decisive role is played by the motor component, which is based on concepts such as technical skills, motor memory, automaticity, anticipation, etc. [2, 5, 6]. The omission of these components from the process of testing makes it absolutely meaningless when it comes to specific coordination abilities and agility $[38,39,40]$; in this case, such testing does not meet the validity criterion and does not ensure its relationship with the phenomenon being assessed $[4,18]$.

\section{Testing coordination using sense of time}

For the purpose of an integrated assessment of the ability to regulate the dynamic, spatial, and time characteristics of movements as well as maintain the sense of tempo and rhythm, we used a complex test, which included dummy throws performed according to a strictly defined programme. The analysis of the obtained data indicates a certain validity of the indicators included in the test programme. The time of 10 sweeps of the dummy at the maximum possible pace for the tested athletes ranged from 12.2 to $22.5 \mathrm{~s}$ with an average value of $17.5 \mathrm{~s}$. A moderate correlation $(\mathrm{r}=0.47)$ was found between the athletes' skill level and test time at maximum speed.

When the test programme was performed with a task to increase the time of performance by 1.5 times, the errors in the subjective perception of time ranged from 0.47 to $17.8 \mathrm{~s}$ with an average actual time of the performance of the sweeps of $24.9 \mathrm{~s}$, and when the performance time was increased two times, the variation in individual results increased as well (0.99-23.1 s), although the average time required to complete the test remained almost the same ( $24.8 \mathrm{~s})$. The correlation between the rating of the athletes and their ability to estimate time was low as the correlation coefficients were 0.37 and 0.34 , respectively. A number of elite athletes were significantly inferior in terms of these indicators to less qualified athletes.

These results seem difficult to understand, given the extremely high significance of the abilities evaluated by this test and its specificity. The relatively low validity of the test could be explained by the fact that the athletes' training programme 
lacked exercises which require constant control of time required to perform motor actions, and thus the athletes were not aware of the relationship between the subjective perception of time needed to perform motor actions and its actual value. It is known that athletes specialising in sports such as swimming or running, where they have the constant opportunity to compare subjective sensations with actual time values, have an exceptionally well-developed sense of time, which is closely related to their skill level [41].

In the programme of each of the 20 training sessions, we included double testing according to the described programme, and the athletes were informed about the time required to perform each of the test parts. Repeated testing of all subjects eliminated the seeming contradictions. First, the variation in the performance time for each of the test parts was significantly reduced, and the average value of the error between the subjective perception of time and its actual values almost halved. Secondly, the magnitude of the correlation between the rating of the athletes and their sense of time significantly increased, which is understandable given the level of technical skill and the amount of muscle memory of more qualified athletes [10, 42].

\section{Integral specific tests for assessing coordination and agility}

We subjected to experimental verification the programmes of three specific tests which included various special motor actions characteristic of hand-to-hand combat: high-speed movements, somersaults, falls, stops, movements in different directions, as well as various punches, kicks, and throws using a dummy.

The programme of motor actions was the same in all three tests and included sequential movement from the starting line to each of the eight test stations (punch bags and pears, makiwara, wrestling dummies, etc.) with the execution of a diverse and strictly specified programme of motor actions that ended with a return to the starting point. The differences between the tests are described below.

- $\quad$ The first test included sequential movement to each of the consecutively placed stations (from 1 to 8 ) with a return to the starting point after each station. Subjects were familiarised with the test programme and were able to try it.

- The second test included the same motor actions as the first, but the order of placement of the stations was arbitrarily changed (marked with numbers) and was unknown to the subjects. The athlete could see the numbers and form the order of movements only after the test started. This required agility from the subject in that part, which was associated with the type of attention, its range, direction, and plasticity; concentration; the speed of simple and complex reactions; and operational memory [14]. The athlete had to perform the test by sequentially moving from the first station to the eighth one.

- The third test was identical to the second one with regard to the test programme; however, movement to each of the stations could be performed in any sequence, and the only requirement was the execution of the task at each of the eight stations. The performance of the test was considerably complicated by the fact that four athletes were simultaneously subjected to testing and formed individual schemes for movement between the stations, thereby creating unexpected situations for each other. The test required not only attention, concentration, speed of response, and operational memory, but also a number of coordination abilities: orientation in space and time, static-dynamic stability, ability for real-time adjustment of the motor programme, and space-time anticipation [10, 39].

Table 2. Correlation coefficients between athletes' rating and their results in specific tests $(\mathrm{n}=16)$

\begin{tabular}{|c|c|}
\hline Specific test & Rating \\
\hline First & $0.59^{*}$ \\
\hline Second & $0.61^{*}$ \\
\hline Third & $0.54^{*}$ \\
\hline
\end{tabular}

Note: * correlation coefficient

According to the data obtained, there was a statistically significant correlation $(\mathrm{p}<0.05)$ between the athletes' skill level and the results of all three tests (Tab. 2). The highest correlation was found for the second test $(r=0.61)$, and the lowest one was between the athletes' skill level and the results of the third test $(\mathrm{r}=0.54)$, which was the most difficult with regard to determining the sequence of the execution of all eight tasks.

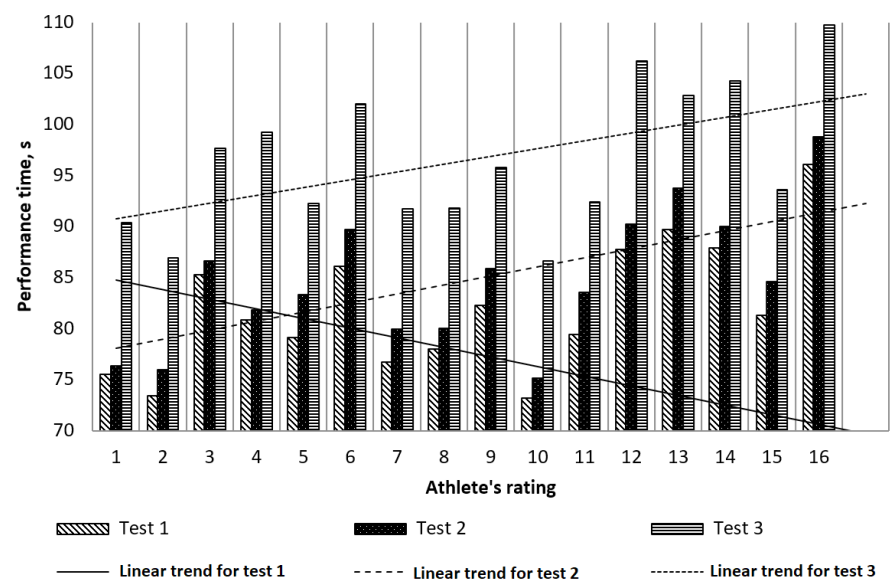

Figure 1. Relationships between the athlete's rating according to skill level and performance time of the tests

If we analyse the individual indicators for each athlete (Fig. 1 ), then there is a clear tendency for performance time to increase for all three tests with a decrease in the athletes' skill level. Furthermore, athletes with higher qualifications had the lowest difference between the performance times of the first and the second tests, which indicates a high level of agility associated with the type of attention, its range, direction and plasticity; concentration; speed of simple and complex reactions; and operational memory. On average, the differences between the performance times were 2.7 seconds for the second and the first tests, 11.7 seconds for the third and the second ones, and 14.4 seconds for the third and the first ones.

\section{Conclusions}

Agility and coordination are the key qualities in combat sports and martial arts. Often, these terms are used as synonyms, but agility, in contrast to coordination, involves not only the execution of motor actions with a complex dynamic and spatial-temporal structure, but must also contain elements of unexpectedness and requires ingenuity in complex motor situations.

In the scientific and methodological literature, very little attention is given to the methodology of the development 
of these qualities. In some studies, agility or coordination are measured using wrong, ineffective tests which do not include sport-specific motor activity or lack the element of unexpectedness. Furthermore, computer software is often used in sports for testing cognitive and psychomotor abilities based on the assessment of eye-hand coordination. Our study has demonstrated the low efficiency of such tests for agility assessment in athletes: for combat sports athletes, a significant correlation was found only between the reaction to a moving object and the level of athletic skill. As for the other tests, active computer users can show much better results than top-class athletes.

Coordination abilities should be tested with the use of specific tasks related to an athlete's training and competitive activity (in terms of the speed of performing motor actions; the time of mastering techniques; the accuracy of motor actions with relation to dynamic, spatial, and temporal characteristics; the consistency of performance, etc.). We have proposed a test for assessing coordination using the sense of time, which includes the performance of 10 throws of the dummy at a given pace: with a maximum speed or with a speed of 1.5 or 2 times lower than the maximum one. A moderate correlation $(r=0.47)$ was found between the athletes' skill level and the time required to perform the test at maximum speed (on average, the test was performed in $17.5 \mathrm{~s}$ ). When the speed of performance was 1.5 times slower than in the initial test, the error in the subjective perception of time varied within the range of 0.47 to $17.8 \mathrm{~s}$, and when the speed was 2 times slower, the error was within the range of 0.99 to $23.1 \mathrm{~s}$. The correlation between the athletes' rating and their ability to estimate time was low ( 0.37 and 0.34 , respectively), which may be explained by the lack of exercises requiring time control in the training programme for combat sports athletes.

Agility testing should be based on the assessment of the effectiveness of motor actions in difficult, unexpected, and hardly predictable situations. We have proposed three specific tests for assessing agility in combat sports athletes that have a sport-specific motor structure and include the element of unexpectedness. The results of agility testing demonstrated a statistically significant correlation between performance in all three tests and athletes' skill level.

\section{Literature}

1. Platonov V.N. (2017). Motor qualities and physical training of athletes. Kyiv: Olimpiyska Literatura. [in Russian]

2. Nimphius S. (2014). Increasing agility. In: D. Joyce and D. Lewindon (eds), High-performance training for sports (pp. 185-198). Champaign, IL: Human Kinetics.

3. Jeffreys I. (2014). Agility development in youths. In: R.S. Lloyd, J.L. Oliver (eds), Strength and conditioning for young athletes: Science and application (pp. 107-119). London, New-York: Routledge.

4. Plisk S.S. (2008). Speed, agility, and speed-endurance development. In: T.R. Baechle and R.W. Earle (eds), Essentials of strength training and conditioning. Champaign, IL: Human Kinetics.

5. Bernshteyn N.A. (1991). On agility and its development. Moscow: Fizkultura i Sport. [in Russian]

6. Keller B.C., Platonov V.N. (1993). Theoretical and methodological principles of athletes' preparation. Lviv: SportART. [in Russian]

7. DeWeese B.H., Nimphius S. (2016). Program design technique for speed and agility training. In: G.G. Haff, N.T. Triplett (eds), Essentials of strength training and conditioning (pp. 521-558). Champaign, IL: Human Kinetics.
8. Ter-Ovanesyan A.A., Ter-Ovanesyan I.A. (1995). Advancement of sports mastery. Moscow: SAAM. [in Russian]

9. Hoffman J.R. (2012). NSCA's guide to program design. Champaign, IL: Human Kinetics.

10. Gamble P. (2013). Strength and conditioning for team sports: Sport-specific physical preparation for high performance. 2nd ed. New York: Routledge.

11. Weynberg R.S., Gould D. (2001). Foundations of sport and exercise psychology. Kyiv: Olimpiyska Literatura. [in Russian]

12. Nikitin S.N. (1990). Technical and tactical training of beginner wrestlers based on the targeted development of agility. [Abstract dis.] Leningrad: Gosudarstvennyy Ordena Lenina i Ordena Krasnogo Znameni Institut Fizicheskoy Kultury Imeni P.F. Lesgafta. [in Russian]

13. Frizen V.E., Rudov V.A. (2003). Adaptation of young wrestlers to motor activity in probabilistic conditions. In: Anniversary Scientific and Practical Conference "Physical culture and sport in the context of modern socio-economic transformations in Russia" - Book of abstracts. Moskva: VNIIFK, pp. 114-115. [in Russian]

14. Boychenko N.V., Shan Y.U. (2013). Specifics of improvement of coordination abilities in combat sports. In: 9th International Scientific Conference "Problems and prospects of sports and martial arts in higher educational institutions" - Book of abstracts, lst ed., pp. 53-55. [in Russian]

15. Boychenko N.V., Mashkevych P.Ye. (2013). Active games in young wrestlers' preparation. In: 9th International Scientific Conference "Problems and prospects of sports and martial arts in higher educational institutions" - Book of abstracts. Belgorod-Kharkov-Krasnoyarsk-Moscow: KGADI, pp. 59-61. [in Russian]

16. Ashkinazi S.M. (2014). Pedagogical conditions, rules and factors of effective teaching hand-to-hand fight. Theory and Practice of Physical Culture, 9, 14-19.

17. Romanova T.V. (2006). Improvement of coordination abilities of elite female athletes in wrestling through aerobics [Abstract dis.] Moscow: RSUFKST. [in Russian]

18. Tanner R.K., Gore C.J. (2013). Quality assurance in exercise physiology laboratories. In: R.K. Tanner, Gore C.J. (eds), Physiological tests for elite athletes (pp. 3-10), 2nd ed. Champaign, IL: Human Kinetics.

19. Godik M.A., Skorodumova A.P. (2010). Integrated control in team sports. Moscow: Sovetskiy Sport. [in Russian]

20. Osborne M.A., Chapman D.W., Gardner S.A. (2013). Ergometer-based maximal neuromuscular power. In: R.K. Tanner, Ch.J. Gore (eds), Physiological tests for elite athletes (pp. 45-57), 2nd ed. Champaign, IL: Human Kinetics.

21. Makarenko M.V. (2006). Basics of professional selection of military experts and methods of studying individual psychophysiological differences. Kyiv: Bogomoletz Institute of Physiology of NAS of Ukraine. [in Russian]

22. Boyko V.F., Danko G.V. (2004). Physical training for wrestlers. Kyiv: Olympic Literature. [in Russian]

23. Gabbett T.J., Duthie G.M. (2013). Rugby league players. In: R.K. Tanner, C.J. Gore (eds), Physiological tests for elite athletes (pp. 371-378), 2nd ed. Champaign, IL: Human Kinetics.

24. Sheppard J. (2014). Optimising training for jumping and landing. In: D. Joyce, D. Lewindon (eds), High-performance training for sports (pp. 167-184), 1st ed. Champaign, IL: Human Kinetics. 
25. Triplett N.T. (2012). Speed and agility. In: T. Miller (ed.), NSCA's guide to tests and assessments (pp. 253-274), lst ed. Champaign, IL: Human Kinetics.

26. Higman D.G., Pyne D.B., Mitchell J.A. (2013). Rugby union players. In: R.K. Tanner, C.J. Gore (eds), Physiological tests for elite athletes (pp. 379-396), 2nd ed. Champaign, IL: Human Kinetics.

27. Portus M., Kellett A., Karppinen S., Timms S. (2013). Cricket players. In: R.K. Tanner, C.J. Gore (eds), Physiological tests for elite athletes (pp. 289-297), 2nd ed. Champaign, IL: Human Kinetics.

28. Rechichi C., Polglaze T., Spencer M. (2013). Hockey players. In: R.K. Tanner, C.J. Gore (eds), Physiological tests for elite athletes (pp. 331-340), 2nd ed. Champaign, IL: Human Kinetics.

29. Burgess D.J., Gabbet T.J. (2013). Football (soccer) players. In: R.K Tanner, C.J. Gore (eds), Physiological tests for elite athletes (pp. 323-330), 2nd ed. Champaign, IL: Human Kinetics.

30. Akhmedova Ye. A. (2016). National types of wrestling in preparation for Olympic and international competitions. Fizicheskaya Kultura: Vospitaniye, Obrazovaniye, Treniro$v k a, 2,38-39$. [in Russian]

31. Shulika Yu.A., Koblev Ya.K., Nevzorov V.M., Skhalyakho Yu.M. (2006). Judo. The system and the wrestling technique. Rostov-on-Don: Feniks. [in Russian]

32. Ivanov I.I. (2004). Greco-Roman wrestling: Textbook for sports schools, faculties of pedagogical institutes, technical schools of physical culture, and schools of Olympus reserve. Rostov-on-Don: Feniks. [in Russian]

33. Spiridonov E.A. (2006). Improvement of coordination abilities when changing combat sports. [Abstract dis.] Almaty: Kazakh State Academy of Sport and Tourism. [in Russian]
34. Kolenkov O.V. (2007). Modelling of special physical preparedness of elite wrestlers in the final macrocycle at the stage of maximum realisation of individual capabilities. [Abstract dis.] Kyiv: NUPESU. [in Russian]

35. Yagello V. (2003). Theoretical and methodological foundations of the system of multi-year physical preparation of young judokas. [Abstract dis.] Kyiv: NUPESU. [in Russian]

36. Tsotsos L.E., Roggeveen A.B., Sekuler A.B., Vrkljan B.H., Bennett P.J. (2010). The effects of practice in a useful field of view task on driving performance. Journal of Vision 10(7), 152-154.

37. Sheppard J.M., Young W.B. (2006). Agility literature review: Classifications. Training and testing. Journal of Sports Sciences 24(9), 919-932.

38. Nikitenko A. (2017). Agility and coordination in the system of physical training for athletes specialising in wrestling and martial arts. Science in Olympic Sport 4, 4-16. [in Russian]

39. Platonov V.N. (2015). The system for preparing athletes in Olympic sport. General theory and its practical applications: Textbook for coaches. Kyiv: Olympic literature, Vol. 2, 752. [in Russian]

40. Jeffreys I. (2014). Agility development in youths. In: R.S. Lloyd, J. L. Oliver (eds), Strength and conditioning for young athletes: Science and application (pp. 107-119), lst ed. London; New York: Routledge.

41. Platonov V.N. (2011). Sports swimming: A way to success. Kyiv: Olympic Literature. [in Russian]

42. Tropp X., Alaranta X., Renstrom P. (2002). Training proprioception and coordination in injury prevention. In: P. Renstrom (eds), Sports injuries. Basic principles of prevention and treatment (pp. 234-245), 1st ed. Kyiv: Olympic Literature. [in Russian]

Submitted: February 21, 2019.

Accepted: August 19, 2019. 